\title{
“CADA MACACO NO SEU GALHO?" Poder, identidade e segmentação de mercado no movimento homossexual
}

\section{Isadora Lins França}

\section{Introdução}

Este trabalho tem por objetivo explorar, por meio de um estudo de caso, possíveis caminhos para a compreensão das relações entre o movimento homossexual e o mercado de consumo segmentado direcionado a homossexuais em São Paulo. Trata-se de analisar as discussões em torno da atuação de travestis no movimento, por intermédio de uma ação dirigida a uma parcela do mercado de consumo segmentado, numa situação que parece desestabilizar os fundamentos sobre os quais se assentou o movimento homossexual no Brasil. Com isso, busco levantar questões pertinentes à compreensão do movimento homossexual contemporâneo num cenário de fortalecimento de um mercado específico dirigido a homossexuais.

Artigo recebido em març/2005

Aprovado em maio/2005
Vale salientar que o que chamamos de movimento homossexual é, hoje, um sujeito político bastante complexo, formado por múltiplas categorias identitárias, nem sempre movidas pelos mesmos discursos. Sem a consideração dessa problemática, torna-se difícil compreender muitas das posições internas ao movimento no que diz respeito ao mercado segmentado ou mesmo à relação com outros atores sociais que integram o seu campo de ação.

O nascimento do movimento homossexual no Brasil é situado em 1978, com a criação do Grupo Somos, em São Paulo (MacRae, 1985). O grupo seguia uma estratégia política de fortalecimento da identidade homossexual e valoração positiva das categorias "bicha" e lésbica, associadas a uma política fortemente antiautoritária, crítica do Estado e da hierarquização de papéis entre casais do mesmo sexo (MacRae, 1985; Fry, 1982). Já a década de 1980 foi marcada por uma rearticulação desse movimento, que buscou caminhos 
de cooperação com o Estado na luta contra a Aids e abrandou a crítica ao autoritarismo, sem deixar de atribuir valor positivo à categoria de homossexual (Facchini, 2004).

Os anos de 1990 emergem num contexto diferente, em que o pânico em relação à Aids se ameniza, possibilitando o revigoramento de uma militância homossexual calcada em outros discursos e estratégias. Multiplicam-se as categorias nomeadas como sujeitos políticos do movimento: em 1993, surge a expressão "Movimento de Gays e Lésbicas"; em 1995, temos o movimento "GLT" (Gays, Lésbicas e Travestis); e finalmente, em 1999, adota-se em parte do movimento, a partir de São Paulo, a expressão GLBT (Gays, Lésbicas, Bissexuais e Transgêneros) (França, Facchini, no prelo). Também há a iniciativa, mais recente, de utilização da fórmula "diversidade sexual", no intuito de criar um termo que passe ao largo das disputas de identidade, encampada fortemente nos últimos anos por um incipiente movimento que se situa nas intersecções entre movimento estudantil e movimento homossexual.

A incorporação e o deslocamento de segmentos nos nomes que indicam o sujeito político do movimento carregam em si uma intenção de inclusão, mas não dirimem os conflitos entre as categorias agrupadas na sigla, que se relacionam num complexo jogo de posições e estratégias políticas. ${ }^{1}$ Até meados da década de 1990 , o movimento homossexual dizia respeito apenas a gays e lésbicas e, se as últimas não faziam parte da sua denominação mais corrente até 1993, como vimos, eram reconhecidas como integrantes do movimento desde o seu início. ${ }^{2}$ Já as travestis promoveram o seu primeiro encontro em 1993, ganhando visibilidade no movimento e sendo incorporadas ao seu nome em 1995. As transexuais tiveram sua primeira aparição organizada num encontro nacional realizado em 1997 (Facchini, 2002).

A inclusão das categorias "bissexuais" e "transgêneros" (termo que pretendia agrupar travestis e transexuais), entretanto, não se deu pela demanda desses grupos, mas seguiu uma tendência internacional (Facchini, 2002, p. 205). As travestis e as transexuais, de início, não ficaram muito satisfeitas em serem chamadas de transgêneros, ${ }^{3}$ e ainda hoje a Articulação Nacional de
Transgêneros conta com vinte entidades/núcleos especificamente de travestis e onze que se intitulam como de "transgêneros" ou de "travestis e transexuais". A presença de bissexuais sempre foi, por outro lado, assunto controverso no movimento, sendo que muitos militantes preferem utilizar a sigla GLT (Gays, Lésbicas e Transgêneros), pois associam bissexuais a "enrustidos", consideram que não há movimento organizado e menos ainda demandas específicas de bissexuais. Em 2004, surgiram as primeiras iniciativas de formar grupos com reuniões periódicas para a discussão da bissexualidade, forçando a inclusão da temática em fóruns regionais e nacionais do movimento.

Além das grandes categorias presentes na sigla GLBT, há também subgrupos, incentivados pela proliferação de fóruns e listas de discussão na internet e pertencentes principalmente ao segmento dos gays, como o grupo dos ursos, ${ }^{4}$ judeus gays, universitários, advogados gays, barbies, ${ }^{5}$ jovens homossexuais etc. É também neste clima de um apanhado de identidades convivendo no movimento e na cena homossexual - virtual ou não - que ganha corpo um vigoroso mercado destinado a homossexuais em São Paulo, ${ }^{6}$ cuja expressão mais visível é um circuito de estabelecimentos comerciais de lazer que se expande a partir do Centro Velho, já tradicional reduto desse circuito, para as áreas mais ricas da cidade, como o eixo Jardins-Paulista, com braços a espraiar-se para bairros como Moema e Vila Madalena.

A década de 1990, além da expansão deste circuito - então também já conhecido como GLS7 - trouxe consigo uma configuração diferente do "gueto" homossexual de outrora: os espaços de consumo e sociabilidade passaram a incorporar em certa medida o discurso político do orgulho e da visibilidade, explicitando o seu direcionamento a um público de orientação sexual determinada e incorporando símbolos popularizados pelos militantes, como a bandeira do arco-íris. Assim, perde força a grande diferenciação estabelecida pelo movimento a partir da "invisibilização" dos homossexuais pelo "gueto", e também as fronteiras do que pode ou não ser considerado atuação política. Atores que a rigor constituiriam o mercado segmentado também começaram a ser vistos e a se considerarem - como articuladores de uma ação política, estimulando a "auto-estima dos 
homossexuais" e a formação de uma "identidade positiva" - mediante iniciativas como festivais de cinema, editoras e mesmo espaços de lazer e sociabilidade - e circulando informações dentro da "comunidade", por meio de sites e revistas especializadas. As tensões com o movimento ainda permaneceriam, mas de uma forma muito mais ambígua do que no período anterior.

Outra novidade trazida pela última década foi a segmentação de espaços de consumo destinados a cada subgrupo desse público: existem não só os bares especializados para lésbicas e gays, mas também para lésbicas "modernas", para as que ouvem MPB, para ursos, para homossexuais mais velhos, cruising bars, ${ }^{9}$ estabelecimentos que recebem fetichistas e sadomasoquistas, entre outros (Simões, França, no prelo). Dentro desse espectro do circuito GLS figuram algumas dezenas de saunas destinadas à troca sexual entre homens, cenário a partir do qual se desenrola o caso aqui discutido. A reivindicação de travestis da Secretaria de Transgêneros da Associação da Parada do Orgulho GLBT de São Paulo, exigindo a entrada numa dessas saunas, originou o drama social analisado na terceira parte deste trabalho. Trata-se de uma ocasião em que as tensões entre as categorias que compõem o "movimento GLBT" e o mercado de consumo segmentado tornaramse explícitas.

\section{Identidades coletivas associadas à ação política}

A construção de identidades coletivas associadas à ação política traz à tona o problema central dos processos pelos quais determinados atores sociais emergem na condição de sujeitos políticos. Vimos como processos de multiplicação, disputas e reacomodações de segmentos têm se tornado comuns no movimento homossexual brasileiro. A emergência de novos atores reivindicando-se como constituintes do sujeito político do movimento - como atesta a recente organização de travestis, transexuais e bissexuais - evidencia a fragilidade de perspectivas teóricas que lidam com as identidades coletivas como elementos estáveis e internamente homogêneos. Esses processos, fornecidos pelo movimento em geral e pelo mercado segmentado, devem ser compreendidos como parte de um contexto mais amplo, exigindo uma abordagem dos arranjos de poder que dê conta do dinamismo com que se alternam posições de "superioridade" e "inferioridade" e da possibilidade de que um mesmo ator social protagonize relações em que aparece simultaneamente como "dominante" ou "subordinado", a depender do referencial adotado. ${ }^{10}$

Para Judith Butler (1998), as posições de sujeito existem sempre em referência a estruturas discursivas mais amplas, e é isso que confere a dimensão política da ação desses sujeitos: a possibilidade de transformar, por meio de deslocamentos e sobreposições, estruturas anteriores a si mesmos e das quais também é um efeito. Essas transformações não podem ser compreendidas como unilineares ou previsíveis: expandem-se para além do controle do sujeito e da sua intencionalidade. Ocorre, portanto, que determinado sujeito político "não é base, nem produto, mas a possibilidade permanente de um certo processo de re-significação, que é desviado e bloqueado mediante outro mecanismo de poder, mas que é a possibilidade de retrabalhar o poder" (Butler, 1998, p. 31). A mesma autora afirma que "[...] se a política não fosse mais compreendida como um conjunto de práticas derivadas dos supostos interesses de um conjunto de sujeitos prontos, uma nova configuração política surgiria certamente das ruínas da antiga" (Butler, 2003, p. 213).

A partir dos dilemas e das críticas esboçados, Joshua Gamson (1998) delineia alguns dos debates presentes atualmente no movimento homossexual nos Estados Unidos - e não seria difícil traçar alguns pontos de coincidência entre o processo norte-americano e o brasileiro. No rastro da discussão sobre a construção de identidades coletivas, o autor aborda a recente constituição da idéia de queerness: ${ }^{11}$ um termo "guarda-chuva" que procura desestabilizar as identidades de "gay" e "lésbica" e até mesmo de "homem" e "mulher", diluindo fronteiras de grupo, em franca oposição ao que Gamson denomina uma política "étnica/essencialista" (Idem, p. 589).

Uma das armas do ativismo queer tem sido trabalhar a partir das demandas de "bissexuais" e "transgêneros", segmentos potencialmente desestabilizadores tanto de uma divisão estanque entre 
"heterossexuais" e "homossexuais", como entre "homens" e "mulheres", por não se encaixarem exatamente em nenhuma das duas pontas dos pares culturalmente estabelecidos e incorporados pelo movimento. Gamson dedica-se justamente às polêmicas causadas pela presença ativa de "bissexuais" e "transgêneros" no movimento norte-americano, chegando à conclusão de que tanto a política de afirmação de identidades essencialistas como a política de constante crítica e desestabilização dessas identidades são importantes para o movimento, além de possuírem uma rentabilidade diferente a depender das situações em que ambas as estratégias podem ser empregadas. Segundo o autor, o movimento lida simultaneamente com duas fontes de opressão: culturais e institucionais. Para se combater a primeira, a estratégia desestabilizadora de fronteiras e identidades seria mais adequada; já a opressão advinda de elementos institucionais e que gerariam discriminações contra todas as "minorias sexuais" exigiria o estabelecimento de categorias fixas e fronteiras seguras.

A partir dos aspectos indicados anteriormente, como pensar as possibilidades de ação política apresentadas para um movimento social que tem a afirmação de identidades coletivas como fundamento para a determinação de seu sujeito político? Se o processo de constituição de identidades coletivas funciona pela demarcação de diferenças e de exclusões, como lidar com a possibilidade de que, em vez de ser um meio pelo qual se procura desestabilizar os regimes de poder, esse processo possa se tornar mais um instrumento de normatização? Essas questões resultam ainda mais complexas se considerarmos que o movimento homossexual não é um ator isolado no contexto em que se insere e diante do público ao qual se dirige. Se a construção de identidades coletivas sempre foi um aspecto central do movimento homossexual, que procurava reverter o estigma e a depreciação social que se abatia sobre as pessoas que se relacionavam com outras do mesmo sexo, deve-se levar em conta que essas construções nunca se desenvolveram isoladamente, mas sempre em comunicação com outros atores sociais. Descrevi, na introdução deste trabalho, a presença de um mercado segmentado direcionado a homossexuais, e assinalei como os direcionamentos produzidos por esse mercado vêm participando ativamente de um processo de construção de identidades por meio da constituição de espaços de consumo específicos. ${ }^{12}$

As questões levantadas pela análise do caso que passo a expor assemelham-se, de certa forma, à reflexão de Gamson, mas introduzem novos elementos, já que se trata de uma situação em que a discriminação institucional é produto de dinâmicas do próprio movimento e do mercado segmentado com o qual este se relaciona.

\section{Disputando espaços de consumo: o lugar das travestis no "movimento GLBT"}

De acordo com observação realizada em campo, o impedimento do ingresso de travestis em diversos estabelecimentos comerciais tem se mostrado acontecimento corriqueiro no seu cotidiano. ${ }^{13}$ Diante desse fato, a Secretaria de Transgêneros da Associação da Parada do Orgulho GLBT deu início a uma série de visitas a estabelecimentos da cidade de São Paulo, em novembro de 2003 - o que foi denominado de Blitz Trans. As visitas eram sempre compostas pelas travestis, maioria na Secretaria de Transgêneros, e por um militante da Associação da Parada que atuava como advogado.

A idéia do nome adotado para as visitas faz parte de um jogo de palavras que, de algum modo, inverte a idéia de vítimas das blitzes policiais que as travestis costumam sofrer na rua. Este raciocínio fica claro na entrevista ${ }^{14}$ realizada com uma das militantes, quando ela conta como surgiu a idéia da Blitz Trans:

[...] um dia a Vanessa ${ }^{15}$ falou: "eu queria fazer uma blitz, sair prendendo todo mundo que discrimina a gente". [...] Ela só não sabe passar isso pra gente de uma forma séria, ela passa brincando, mas é super válido o que ela fala. [...] E a Carla: "opa! Mas dá pra gente sair, a gente pode sair visitando estabelecimentos, e tal". E aí, nós pegamos a lei $10.948^{16}$ que protegia a gente e fomos visitando estabelecimentos por aî".

O que conferia um caráter irônico à "brincadeira" de Vanessa era justamente a disparidade entre o sujeito que é vítima de uma ação e a suposta impossibilidade de que se coloque como autor da 
ação, gerando um contraste de significados que provoca o riso. Levar essa idéia a sério provocou um efeito de inversão que tirava as travestis da qualidade de vítimas, para apresentá-las na qualidade de agentes contra o próprio preconceito que sofriam.

Um dos poucos estabelecimentos que se negou a receber as travestis após a apresentação da lei e uma breve negociação foi uma sauna destinada ao público homossexual masculino, o que gerou grande mobilização em torno do assunto, suscitando, no movimento homossexual em geral e entre usuários do site de mídia segmentada MixBrasil, debates acalorados que são o foco da presente análise. ${ }^{17}$ A sauna em questão, com grande presença de michês entre seus freqüentadores, é uma das mais antigas desse tipo ${ }^{18}$ em São Paulo, fundada em 1982 (Trindade, 2004, p. 179). O dono do local havia se recusado a receber as travestis, alegando que "a sua presença agredia os demais freqüentadores da casa, criando incômodo e embaraço". ${ }^{19}$

É importante que se recorra aos argumentos nos quais se apóiam as demandas das travestis, a fim de que seja possível compreender como se inserem nas reivindicações do movimento homossexual. A respeito dessas reivindicações podemos ler, no site da Secretaria de Transgêneros:

[...] estamos lutando pelo direito de ir e vir que nos está sendo tirado. [...] Reflita sobre a Lei 10.948 mais especificamente no Artigo $2^{\circ}$ que diz: "Consideram-se atos atentatórios e discriminatórios dos direitos individuais e coletivos dos cidadãos homossexuais, bissexuais ou transgêneros, para os efeitos desta lei: proibir o ingresso ou permanência em qualquer ambiente ou estabelecimento público ou privado, aberto ao público".

Pode-se depreender dessa passagem que as ações das militantes pleiteiam direitos de cidadãs plenas, como o direito de ir e vir, que a elas é vetado, já que não podem entrar em todos os lugares abertos ao público. O que confere concretude a essa reivindicação política é a demanda de poder entrar livremente em estabelecimentos comerciais, na qualidade de consumidoras comuns.

Pude observar que o impedimento de acesso a estabelecimentos comerciais de lazer e serviços é causa de imensas frustrações para as traves- tis, tornando o seu cotidiano muito difícil, mesmo nas tarefas que aparecem como as mais prosaicas para outras pessoas. Uma travesti participante da lista GLS, espaço de discussão virtual de militantes, faz as seguintes observações:

Vc já levou uma escopeta no meio das pernas porque a polícia acha que seu carro é bom demais para um viado e deve ser roubado? Vc já foi constrangido em local público que está pagando para entrar?? [...] Estes que cito são os nossos problemas corriqueiros.

Dessa forma, as travestis da Secretaria de Transgêneros viam nos protestos e na negociação com esses estabelecimentos uma estratégia política que não só adquiriria visibilidade na mídia pelo seu caráter de novidade, ${ }^{20}$ mas também teria o potencial de aglutinar outras travestis em torno de uma proposta política.

Uma das principais articuladoras do protesto das travestis, em mensagem no fórum do site MixBrasil, expressa a idéia de que o poder de consumo pode ser um marcador de igualdade de direitos e deveres:

A casa vive das entradas (os boys também a pagam) e da consumação dos bares. E por acaso travesti vai entrar de graça? NÃO! Travestis não são boas consumidoras? [...] Aqui a grande maioria de nós tem apartamentos e carro importado. Agora pergunto: eu, como travesti, não tenho direito a freqüentar uma sauna de prostituição e pegar meu bom michê para gozar?

Em reunião da Secretaria de Transgêneros, ouvi afirmações de que "quando são feitas as Blitz Trans, a Secretaria enche de travestis, porque elas são muito imediatistas e vêm ao movimento buscando vantagens imediatas", "viram a possibilidade de entrar em lugares em que antes eram barradas" e "a travesti tem como objetivos de vida, marido, peito e dinheiro". Apesar de o interesse das travestis nas Blitz Trans ser qualificado como "imediatista", é possível que esta estratégia também atraia as travestis porque elas aparecem como cidadãs que fazem um protesto justamente por estarem numa posição bem-vista socialmente, a de consumidoras, e não somente como vítimas da discriminação. 
Devem-se destacar também, no parágrafo anterior as cores com que são descritos os anseios de inclusão social das travestis: marido, peito e dinheiro. Don Kulick (1998), em seu estudo etnográfico sobre o universo das travestis em Salvador, descreve em minúcias como estes são aspectos cruciais para as travestis, envolvendo o uso indiscriminado e perigoso, do ponto de vista da saúde, do silicone industrial e hormônios, com o qual as travestis adquirem formas femininas, que também aumentam suas chances de ganhar dinheiro com a prostituição; ${ }^{21}$ a complexa relação de poder que elas desenvolvem com os "maridos", desempenhando ao mesmo tempo o papel de "esposas submissas" e de "provedoras do lar"; 22 e o dinheiro, outra preocupação fundamental para as travestis, não só porque, como todo mundo, precisam atender às suas necessidades básicas de "comer, morar e vestir", mas também porque o dinheiro possibilita o sustento dos maridos, traz a admiração da família e lhes confere um status mais elevado, incluindo-as socialmente como consumidoras. ${ }^{23}$ Esses três aspectos acabam por incentivar-se reciprocamente, constituindo referências essenciais para as travestis.

Butler afirma que a citação da norma dominante, realizada pela figura da travesti, não necessariamente

[...] desloca essa norma, antes, torna-se o meio pelo qual a norma dominante é mais dolorosamente reiterada, como o desejo mesmo e a performance daqueles sujeitos. Claramente, a desnaturalização do sexo, nos seus múltiplos sentidos, não implica uma liberação do constrangimento hegemônico: quando Vênus fala do seu desejo de se tornar uma mulher "por inteiro", de encontrar um homem e ter uma casa nos subúrbios com uma lavadora de roupas, nós poderíamos nos questionar se a desnaturalização do gênero e da sexualidade à qual ela procede [performs], e procede [performs] bem, culmina numa reelaboração da estrutura normativa da heterossexualidade (Butler, 1993, p. 133, trad. livre).

Ocorre, porém, que no caso aqui analisado (numa dinâmica semelhante ao caso interpretado por Butler), se a reivindicação das travestis no sentido de se integrarem à norma dominante de uma forma que reproduz e reitera a própria norma por intermédio dos sujeitos por ela marginalizados não pode ser chamada exatamente de desafiadora da "cultura de consumo" e da "hegemonia heterossexual"; em outro nível de análise, a reivindicação das travestis instaura o questionamento à hegemonia dos gays dentro do próprio movimento e da cena homossexual, como pretendo demonstrar adiante.

Os donos e os freqüentadores das saunas gays (entre os quais não se excluem militantes do movimento), os interlocutores diretos a quem se dirige a reivindicação das travestis, pertencem a um círculo muito próximo a elas. A interdição por parte de um estabelecimento destinado ao público homossexual, entendido naturalmente como um aliado pelas travestis, intensificava a perplexidade das travestis diante do caso, como podemos verificar no site da Secretaria de Transgêneros:

[...] às vezes, nem parecíamos estar falando com o proprietário de um estabelecimento GAY. Fica aqui o nosso repúdio à THERMAS X... ${ }^{24}$ e também nosso pedido de apoio para que absurdos como esse não voltem a ocorrer no meio GLBT (grifo meu).

Assim, por vezes, as travestis também aplicam à sauna um termo do movimento - "meio GLBT" -, quando melhor se aplicaria à lógica do proprietário um termo que segmenta o público do estabelecimento e o reduz a uma "sauna gay" de freqüência exclusiva. No caso das saunas, o que é compreendido pelas travestis como discriminação funciona como o que define o público-alvo consumidor e oferece atrativos a uma clientela mais reduzida, fazendo da exclusividade e da promessa de encontrar de modo quase instantâneo o que se procura (a possibilidade de trocas sexuais entre homens) o seu trunfo comercial. Temos, então, uma típica situação em que o mercado segmentado destinado ao público homossexual entra em conflito com a lógica e o discurso de parte do movimento.

O mercado destinado ao público homossexual tem respondido, e incentivado, uma lógica de multiplicação de identidades no interior da grande categoria "homossexual", mediante a segmentação de espaços de sociabilidade, como descrito na introdução deste trabalho. Dentro desta lógica, as saunas funcionam como um espaço 
específico de interação sexual entre homens que fazem sexo com homens, carregando as divisões entre masculino e feminino e excluindo as travestis, compreendidas como pertencendo a outro grupo que não o dos homens "de verdade". Como não existem espaços de lazer destinados especialmente às travestis, é comum que elas freqüentem espaços "gays" ou "GLS", reconhecendo tais espaços como os mais adequados para si, por compartilharem uma mesma "comunidade" ou "meio". Quando procurei investigar os hábitos de lazer das travestis, isto apareceu com bastante força, como na entrevista com Diana:

Adoro sair, vou pra boate gay. [...] Adoro o público gay, acho que é o nosso público, a gente tem que se identificar com o que é da gente, entendeu? Esse negócio de ficar fazendo linha em lugar de hetero, lugar onde as pessoas não vão respeitar a gente, lugar onde a gente vai ser malvista, eu prefiro estar no meio dos gays, não que no meio dos gays não tenha desrespeito, ou às vezes a gente vai ser malvista, mas ainda assim eu prefiro estar no meio dos gays, que estou no meio do meu povo.

O "meu povo" é o que compõe a sigla GLBT, em que travestis e gays figuram como parte do mesmo público.

Entretanto, mesmo no movimento, o uso da sigla GLBT não dilui as diferenciações, os conflitos e as hierarquizações entre os grupos que a compõem. A articulação política entre as quatro letras da sigla foi construída com base no discurso de que todas as categorias estão sob o signo da discriminação e da exclusão social. Esse foi o ponto de partida para que se reivindicasse solidariedade entre tais categorias para a construção de um sujeito político que pudesse reivindicar direitos para todos os segmentos, e para que a conquista de direitos para cada um fosse compreendida como uma conquista de todos os outros. É esta a relação idealizada pelos militantes do movimento, e que, longe da fórmula ideal, acaba expressando conflitos entre identidades compartimentalizadas.

Em meio a essas disputas, a Parada do Orgulho GLBT situa-se como um evento de visibilidade maciça das demandas do movimento e que promove, intencionalmente ou não, a dilui- ção dessas categorias em meio à multidão diversificada que toma as ruas (Facchini, 2002). A Associação da Parada também é das poucas organizações do movimento a manter grupos que representam as quatro letras do GLBT em constante funcionamento. É compreensível que este seja o discurso reiterado pela sua Secretaria de Transgêneros.

A perspectiva de diluir as fronteiras entre gays, lésbicas, bissexuais e transgêneros quando se trata de unir forças para a ação política também aparece em outras ocasiões, constituindo-se como o principal foco de argumentação daqueles que apoiaram as travestis nesse episódio. O conflito, então, dá-se entre os que adotam esse discurso e entre os que raciocinam no eixo de segmentação e afirmação de cada uma das categorias. Vejamos trecho de mensagem postada no fórum do site MixBrasil:

[...] o que pode ser pior que o preconceito? Simples, o preconceito vindo de quem se diz vítima de preconceito. Não há razão aceitável para impedir as travestis de irem à sauna. [...] Nas passeatas do orgulho gay vemos frases pedindo aceitação e igualdade, mas como levar isso a sério se aqueles que a pedem muitas vezes agem de forma ainda mais reacionária? Como homossexuais podem exigir direitos se ainda hoje agem desta forma com pessoas que deveriam ser suas parceiras na luta pela igualdade?

Atentemos também para a mensagem de umas das lideranças do movimento homossexual em São Paulo, na lista GLS:

Lamentavelmente, sinto que ainda temos uma enorme dificuldade em reconhecer as diferenças existentes dentre os segmentos que compõem o movimento pela diversidade sexual - lésbicas, gays, travestis, transexuais e bissexuais - como um fator de riqueza para nossa causa, e não como motivador para posturas segregacionistas. Bom, não sei quanto aos demais, mas não tenho dúvidas quanto ao meu lugar nessa briga: estarei junto com outras pessoas que acreditam realmente na diversidade sexual em frente às Thermas $\mathrm{X}$..., protestando contra o impedimento de ingresso de travestis e transexuais naquele estabelecimento. SOMOS TODAS E TODOS TRAVESTIS E TRANSEXUAIS! (grifos meus). 
O nosso problema torna-se mais complexo quando, dentro do mesmo movimento GLBT, vemos atuar a lógica de segmentação semelhante à do mercado, enfraquecendo a reivindicação das travestis e reduzindo-a ao particularismo de um grupo marcado, que invade o espaço dos gays. Essa postura pode ser vista como uma estratégia de reforço de uma hegemonia ameaçada pelas demandas das travestis, mesmo que não seja conscientemente articulada nesses termos. Passemos então aos argumentos que a sustentam.

Uma das questões que serve de subtexto aos que criticam as travestis é o que pode ou não ser reivindicado, o que é legítimo como ação política. Vale lembrar que as manifestações das travestis contra a violência policial, por exemplo, são acolhidas quase inquestionadamente pelo movimento homossexual. Em contraposição ao protesto contra as saunas, qualificado como "populista" por militantes, os protestos contra a violência são encarados como assunto grave, talvez por enfatizarem o aspecto de que as travestis são "vítimas da homofobia", por dirigirem-se ao Estado (um campo mais tradicional de luta política do que o mercado) e, por fim, por estabelecerem uma oposição entre homofobia heterossexual versus direitos humanos de homossexuais/travestis, diferente do protesto das saunas, que questiona o potencial de inclusão da cena gay.

Das hipóteses levantadas, o último ponto é o que aparece com mais clareza nos argumentos utilizados pelos militantes. Questionando a validade política da reivindicação das travestis, surge inicialmente, e como ponto pacífico, a idéia de que a sauna freqüentada por homossexuais é um espaço de troca masculina, visto de forma positiva pelos militantes, e que deve ser preservado como tal. Nas palavras de um militante histórico do movimento, na lista GLS:

[...] lastimo não concordar com esta manifestação contra a existência de saunas destinadas exclusivamente a homens que têm fantasia sexual com outros varões. [...] Honestamente, minha experiência de militância leva-me a considerar que esse protesto se trata de uma manifestação/postura equivocada, populista, invasiva da diversidade erótico/sexual dos gays - ou "das gays" ou "bichas boys", ou "bichas machudas", ou "bichas frustradas", ou "mariconas", como somos muitas e muitas vezes chamados pelas irmãs transgêneros (grifo meu).

Está claro que a sauna é entendida como um espaço capaz de fortalecer a afirmação identitária de homens que gostam de fazer sexo com outros homens por meio da exclusividade, o que tornaria a presença das travestis "invasiva" desse espaço destinado ao homoerotismo masculino. Também percebemos esse viés de marcar espaços e afirmar identidades pela diferenciação na fala que critica os termos pejorativos empregados pelas travestis para designar os gays.

Jeffrey Weeks (1985, p. 221) afirma que, como reação ao preconceito e à discriminação profundamente enraizados contra práticas sexuais entre homens, houve uma concentração dos homens gays sobre o próprio ato sexual. O autor localiza, na década de 1970, uma grande proliferação de saunas e outros estabelecimentos comerciais destinados especificamente a trocas sexuais, como expressão de uma necessidade pessoal, representando a busca pela afirmação de uma sexualidade negada. A abordagem de Weeks condiz com a posição de parcela dos militantes gays, que expressam visão semelhante em relação às saunas e a lugares correlatos: são espaços de afirmação de desejos e práticas homossexuais. Em mensagem de um militante à lista GLS, é visível que se discute um problema de preservação de identidades e do seu conteúdo descritivo:

Enfim, trata-se de uma sauna gay, com identidade masculina. Precisamos discutir isto detalhadamente. Também defendo que em locais públicos todos e todas devem entrar. Agora em locais privados, voltados para clientes categorizados, a coisa complica.[...] Precisamos discutir bem os limites, as identidades e os espaços, precisamos ir no fundo do tacho nesta discussão.

Está claro que, enquanto as travestis demandam a entrada nos estabelecimentos comerciais destinados ao sexo entre homens com a justificativa de que não deve haver espaços exclusivos no interior da cena homossexual, os militantes gays que criticam esta demanda percorrem um caminho diametralmente oposto: é preciso estabelecer limites, identidades e espaços. A partir da definição desses termos, outra sentença recorrente no 
fórum de mensagens do site MixBrasil seria possível: "cada macaco no seu galho!".

É exatamente no intuito de dissecar categorias que é construída a outra leva de argumentos contra a presença das travestis nas saunas. As mais intrincadas taxinomias são aplicadas às travestis. Os espaços rígidos do feminino e do masculino socialmente estabelecidos, demarcados pela matriz heterossexual, são utilizados pelos militantes homossexuais na tentativa de situar as travestis em um ou outro terreno, determinando os espaços onde sua presença seria lícita. Alguns militantes da lista GLS falam da "presença de homens com peito de mulher", que "todas querem ser tratadas como uma mulher, serem olhadas como uma mulher, seduzir os homens como mulheres". Ou ainda: "qual a identidade de gênero das travestis? Elas querem ser tratadas por $o$ travesti ou $a$ travesti? Elas querem usar banheiro masculino ou feminino? No shopping, vão na seção de roupa feminina ou masculina?".

Quando se trata do fórum de discussão do site MixBrasil temos, outros comentários do mesmo tipo: "Não sou contra a freqüência de travestis gays em saunas gays. Mas existem travestis heterossexuais... O que dizer desses?"; "Não me sentiria bem se encontrasse com homens maqueados, vestidos de saias, e coisas assim". Neste trecho, mais uma vez, vemos tensões geradas pela desestabilização promovida pelas travestis sobre a adequação entre identidade de gênero e identidades sexuais, e as configurações corporais que devem funcionar em consonância com ambas. Como estratégia política, as travestis fizeram uso consciente deste potencial de desestabilização, ameaçando irem de roupão de banho ao protesto organizado em frente à sauna, que não chegou a se concretizar, visto que o dono do estabelecimento liberou a sua entrada após tamanha polêmica. Segundo Diana: "eu falei [ao dono]: "eu vou vir de roupão! Porque eu quero entrar na sauna, está todo mundo aqui de roupão, eu quero vir de roupão. Aí, ele ficou em pânico". De início, as travestis jogaram com o choque que o uso dos mesmos trajes dos clientes, associados a um corpo feminino, poderia causar. Posteriormente, Diana conta que ela e mais cinco travestis foram à sauna "todas de biquíni. O povo ficou em pânico". Podemos perceber que a questão das confi- gurações corporais e das aparências relacionadas às convenções de gênero também são fundamentais para as travestis, mas que elas fizeram um uso estrategicamente desestabilizador e provocativo dessas normas. A configuração de pânico que essa desestabilização poderia causar e o seu uso politicamente estratégico mostraram-se muito claramente nas suas falas.

\section{Considerações finais}

Constitui o problema aqui analisado um jogo de complexas relações das quais este texto foi uma tentativa de aproximação, inspirado na perspectiva teórica já exposta. Neste caso, imbricamse as lógicas de um grupo de travestis, que demanda o direito de freqüentar estabelecimentos destinados ao público homossexual; de atores do mercado segmentado, que recusam a sua presença, no intuito de preservar um nicho de consumidores; de uma parcela de gays, militantes e nãomilitantes, que é a favor da reivindicação das travestis e adota o discurso da diversidade sexual e não segmentação; e de outra parcela, que defende os estabelecimentos exclusivos para a interação entre homens, como uma maneira de afirmação da identidade homossexual. O instrumental teórico apresentado na segunda parte do texto possibilitou a compreensão de uma ação política considerando os diversos níveis em que esta desenvolve relações de poder e se articula socialmente. Se tivermos em mente que essas relações não são estáticas, e sim dinâmicas e intercomunicáveis, é possível entender que, em contextos diversos, a reivindicação das travestis seja interpretada de maneiras diferentes, adquirindo também diferentes significados políticos.

Essa orientação estende-se também à composição do sujeito político do que se convencionou chamar "movimento GLBT", na medida em que o movimento se articula sob a lógica da negociação entre diferentes identidades. A situação de disputa política não se restringiu a mudanças de posição entre sujeitos dados e definidos, mas expressou o caráter contingente das alianças que se estabelecem no interior de um determinado sujeito político. Enquanto uma parte do movimento composta pelos gays abraçava a demanda 
das travestis e a alçava a um status de reivindicação de direitos civis, outra parte esforçava-se por jogá-la no terreno dos particularismos, considerando-a invasiva de outros direitos. Apresentou-se muito claramente, então, a questão do que pode ou não ser considerada reivindicação legítima, e de como forças variadas e desiguais determinam o que será ou não reconhecido como tal a partir de um conjunto de normas contextuais.

Se, por um lado, os anseios das travestis podem ser compreendidos como uma reiteração da norma, exigindo direitos por meio do consumo e da reiteração de uma determinada posição "de mulher", por outro, suas reivindicações carregam também um caráter subversivo quando instauram o questionamento e a atitude crítica dentro do "movimento GLBT" e desestabilizam as suas estruturas normativas. É particularmente importante para este trabalho o exame da hipótese do que acontece quando um grupo socialmente marginalizado reivindica direitos mediante uma prática específica, e de como isso se torna complicado quando essa demanda tem de ser negociada entre os "aliados naturais".

As travestis foram capazes de instaurar $\mathrm{O}$ questionamento interno das normas que regem a atuação do movimento, utilizando-se do discurso de igualdade e diversidade sexual difundido por parte dos militantes e de uma estratégia desestabilizadora das estruturas que conectam identidades de gênero e identidades sexuais por meio de marcadores corporais. Originaram, assim, uma situação que forçou os próprios limites do movimento, promovendo a discussão e a rearticulação de forças tais que, por si só, poderiam ser consideradas subversivas de uma relação de dominação anteriormente estabelecida. É esse tipo de ação política que Butler localiza como "performativa": o potencial de produzir, no interior de uma mesma forma discursiva, efeitos que deslocam e desestabilizam essa mesma norma, que não lidam com as estruturas de poder como se estivessem fora delas, mas que trabalham essas estruturas de dentro e contra si mesmas (Butler, 1993, p. 241). Procurei demonstrar que o elemento comum às categorias que compõem um sujeito político não se apresenta como um dado advindo da posição inerente a este sujeito, no sentido ontológico do termo, mas como uma articulação e acomodação de diferen- tes demandas internas em relação ao foco de reivindicação estabelecido, produzindo arranjos únicos que podem ser tão eficazes do ponto de vista da ação política direcionada quanto instáveis do ponto de vista das políticas de identidade.

\section{BIBLIOGRAFIA}

BUTLER, J.; LACLAU, E. \& ZIZEK, S. (2003), Contingencia, begemonia, universalidad: diálogos contemporáneos em la izquierda. Tradução de Cristina Sardoy e Graciela Homs. Buenos Aires, Fondo de Cultura Económica.

BUTLER, Judith. (1993), Bodies that matter: on the discursive limits of "sex". Nova York, Routledge.

(1998), "Fundamentos contingentes: O feminismo e a questão do 'pós-modernismo'”. Cadernos Pagu, 11: 11-42.

(2003), Problemas de gênero: feminismo e subversão da identidade. Tradução de Renato Aguiar. Rio de Janeiro, Civilização Brasileira.

FACCHINI, Regina. (2002), "Sopa de Letrinhas"? Movimento homossexual e produção de identidades coletivas nos anos 90: um estudo a partir da cidade de São Paulo. Dissertação de mestrado, Campinas, Universidade de Campinas, IFCH (mimeo).

(2004), "Movimento homossexual e construção de identidades coletivas em tempos de Aids", in A. P. Uziel; L. F. Rios e R. G. Parker (orgs.), Construções da sexualidade: gênero, identidade $e$ comportamento em tempos de Aids, Rio de Janeiro, Pallas.

FRANÇA, I. L. \& FACCHINI, R. (no prelo), "Movimento homossexual no Brasil e políticas de identidade: possibilidades e limites", in P. Ortellado (org.), Pensamento em movimento, São Paulo, Conrad.

FRY, Peter. (1982), Para inglês ver: identidade e politica na cultura brasileira. Rio de Janeiro, Zahar. 
GAMSON, Joshua. (1998), "Must identity movements self-destruct? A queer dilemma", in P. M. Nardi e B. E. Schneider (orgs.), Social perspectives in lesbian and gay studies, Londres, Routledge.

KULICK, Don. (1998), Travesti: sex, gender and culture among brazilian transgendered prostitutes. Chicago, University of Chicago.

MacRAE, Edward. (1985), O militante homossexual no Brasil da "abertura". Tese de doutorado, São Paulo, Universidade de São Paulo, FFLCH (mimeo).

MILLER, Daniel. (1995), "The consumption as vanguard of history: a polemic by way of introduction", in D. Miller (org.), Acknowledging consumption: a review of new studies, Londres, Routledge.

MOUFFE, Chantal. (1992) "Feminism, citizenship, and radical democratic politics", in J. Butler e J. W. Scott (orgs.), Feminists theorize the political, Londres, Routledge.

SIMÕES, J. A. \& FRANÇA, I. L. (no prelo), "Do 'gueto' ao mercado", in J. Green e J. R. Trindade (orgs.), Olhares sobre a homossexualidade masculina em São Paulo, São Paulo, Editora da Unesp.

TRINDADE, José Ronaldo. (2004), "Construção de identidades homossexuais na era Aids", in A. P. Uziel; L. F. Rios e R. G. Parker (orgs.), Construções da sexualidade: gênero, identidade e comportamento em tempos de Aids, Rio de Janeiro, Pallas.

WEEKS, Jeffrey. (1995), Sexuality and its discontents: meanings, myths and modern sexualities. Nova York, Routledge.

\section{Fontes}

Notas de campo.

Lista GLS: listagls@yahoogrupos.com.br.

Site mixbrasil: http://mixbrasil.uol.com.br/extra!/ travs_sauna/travs_sauna.asp acesso em 15 jul 2004.

Site da Secretaria de Transgêneros da Associação da Parada do Orgulho GLBT de São
Paulo: http://www.transgeneros.blogger. com.br/acesso em 15 jul 2004.

\section{Notas}

1 Regina Facchini (2002) descreve em detalhe as disputas e os deslocamentos de categorias ocorridos, nos anos de 1990, no movimento homossexual. Seu trabalho investiga os processos de construção do sujeito político do movimento na última década, fornecendo um panorama bastante completo desses desenvolvimentos.

2 As lésbicas já estavam presentes no primeiro grupo do movimento, o Somos. Após cisão no seu interior, fundaram o primeiro grupo brasileiro voltado exclusivamente para lésbicas, o GALF (Grupo de Ação Lésbica-Feminista), em 1981.

3 Transgêneros é uma categoria traduzida do inglês transgender. Foi difundida no Brasil com a intenção de acolher tanto travestis, como transexuais. O que diferenciaria travestis de transexuais é uma polêmica no movimento: alguns afirmam que a diferença estaria no desejo da cirurgia de transgenitalização; outros, que estaria no desempenho de papel sexual "ativo" ou "passivo"; outros, ainda, ressaltam o sofrimento psíquico que um órgão genital identificado como pertencente ao sexo oposto ao qual se julga pertencer causaria a transexuais, ao passo que travestis lidariam "bem" com este aspecto.

4 Homossexuais do sexo masculino que se identificam com códigos de masculinidade e se contrapõem às barbies por valorizarem gordura e pêlos.

5 Homossexuais do sexo masculino que exibem corpos musculosos e muitas vezes depilados.

6 Daniel Miller (1995) ressalta a importância que as correntes de demanda dos consumidores têm assumido no processo de produção de mercadorias. Segundo Miller, os produtores têm sido instados a criar novas versões de produtos já existentes, atendendo a necessidades específicas e cristalizando nichos de mercado. Esta operação, por sua vez, responderia a uma mudança global rumo ao pluralismo de "políticas de identidade", "regionalismos", "estilos de vida", entre outros, surgidos a partir de maio de 1968.

7 A sigla GLS significa Gays, Lésbicas e Simpatizantes. Criada na primeira metade dos anos de 1990, e é uti- 
lizada principalmente para qualificar o circuito de lazer da cidade, embora hoje também se aplique a outros serviços e até a um determinado "espírito GLS". Para mais informações, ver Facchini (2002, p. 125).

8 De acordo com MacRae (1985), os primeiros militantes homossexuais de São Paulo estabeleciam uma tensa relação com o que denominavam "gueto". Este era, por muitos, considerado o lugar da invisibilidade, tornando possível a criação de um universo onde se poderia "vivenciar a sexualidade" sem que fosse necessário "assumi-la" cotidianamente. Por outro lado, o "gueto" era um dos espaços onde poderiam ser recrutados novos militantes e mesmo este espaço de "vivência da sexualidade" era considerado importante para a autoestima dos homossexuais.

9 Cruising bars são bares destinados à troca sexual entre homens, com uma estrutura especialmente adaptada para isso e de freqüência noturna. Alguns deles condicionam o ingresso dos clientes ao uso de um determinado dress code, ou seja, a obrigação de estarem trajados de acordo com as normas da casa. Podem ser exigidos como dress code o uso de roupas de couro, calça jeans e camiseta branca, entre outros.

10 A este respeito, ver Mouffe (1992).

11 O termo queer, em inglês, pode ser entendido tanto como "esquisito", quanto como algo próximo aos termos brasileiros "viado" ou "bicha". Tem sido usado por uma parcela do movimento norte-americano e europeu com a intenção de abrigar todos e todas que se consideram "fora" da norma heterossexual.

12 O crescimento desse mercado é particularmente forte em São Paulo e tem impacto nas formas de expressão do ativismo homossexual local. A Parada do Orgulho GLBT de São Paulo destaca-se pela presença grande e variada de carros de som das casas noturnas, saunas, sites e outras iniciativas do mercado segmentado, e muitos participantes aglomeram-se em torno dos carros que tocam suas músicas favoritas.

13 A aplicação de sobretaxas para a entrada de travestis nos estabelecimentos também é prática comum: o preço pela sua entrada pode ser multiplicado em até dez vezes em relação aos preços habituais cobrados para outros clientes.
14 Entrevista realizada em dezembro de 2004. Uma das maiores dificuldades em relação à pesquisa etnográfica para este artigo foi a dificuldade de realização de entrevistas com as travestis. A maioria das travestis ativas no caso aqui relatado viajaram para a Europa logo em seguida - e uma delas durante os acontecimentos. Um golpe de sorte tornou possível que esta entrevista com Diana Sanders fosse realizada quando de sua visita ao Brasil no período das festas de final de ano.

15 Todos os nomes dos personagens citados neste artigo são fictícios.

16 A Lei 10.948, aprovada em 2001, com validade no estado de São Paulo, dispõe sobre as penalidades a serem aplicadas a práticas de discriminação contra gays, lésbicas, travestis, transexuais e bissexuais.

17 As fontes utilizadas para a análise serão as mensagens enviadas a uma lista de discussão virtual do movimento, coberturas da mídia especializada no segmento GLBT, mensagens registradas em fórum de debates do site mix brasil, notas de campo e o próprio site da Secretaria de Transgêneros.

18 José Ronaldo Trindade assim divide as saunas destinadas à troca sexual entre homens: há as "saunas privativas de bichas e as saunas de "michês", onde vão os homossexuais que preferem transar com bofes" (Trindade, 2004, p. 179, grifos do autor). Os michês são garotos de programa que não necessariamente identificam-se como homossexuais e que, na maioria das vezes, adotam uma aparência bastante viril. De acordo com sua divisão, a sauna em questão enquadrar-se-ia na segunda categoria.

19 Ver site http://mixbrasil.uol.com.br/extra!/travs_sauna/ travs_sauna.asp.

20 Vale sublinhar que as travestis souberam se utilizar do potencial midiático do assunto, manejando bem as diversas formas de publicização oferecidas por vários meios. Segundo Diana, em entrevista: "eu espalhei pela Internet inteira esse protesto, eu fui no Superpop [show televisivo de variedades, apresentado em horário nobre] da Luciana Gimenez e anunciei o protesto, e o dono da sauna ficou em pânico: 'que bicha é essa que eu fui mexer, que ela está na televisão falando do meu estabelecimento?'. E eu falei o nome, falei o dia e a hora do protesto. No dia seguinte, ele ligou, queria encontrar com a gente, não sei o quê...”. 
21 “'A sorte da gente é que a gente tem silicone'. Eu ouvi travestis afirmando isso vezes e mais vezes. Para as travestis através do Brasil, silicone é um produto miraculoso - algumas delas referem-se a ele como "revolucionário" - que torna possível para elas a aquisição de atributos corporais femininos que em muitos casos são, elas dizem, mais bonitos que os das mulheres" (Kulick, 1998, p. 66, trad. livre).

22 "Vivendo com travestis em Salvador, descobri muito cedo que namorados (geralmente chamados de maridos, [...] mas também chamados de bofes, ocós, homens e machos) são uma preocupação contínua e central nas suas vidas. Namorados tomam uma fatia enorme do pensamento, do tempo e das conversas entre travestis - para não mencionar do seu dinheiro" (Kulick, 1998, p. 97, trad. livre).

23 Kulick observa que "a falta de habilidade para ganhar dinheiro é um infortúnio devastador para uma travesti, tanto em termos materiais como emocionais. Eu vi travestis individualmente tristes em muitas ocasiões [...], mas a única vez em que observei alguma delas sucumbir a um estado de depressão letárgica e autopiedosa foi quando elas não estavam ganhando dinheiro nas ruas" (Kulick, 1998, p. 183, trad. livre).

24 O nome real do estabelecimento foi substituído, neste artigo, pelo nome fictício "Thermas X...". 
"CADA MACACO NO SEU GALHO?": PODER, IDENTIDADE E SEGMENTAÇÃO DE MERCADO NO MOVIMENTO HOMOSSEXUAL

Isadora Lins França

Palavras-chave: Sexualidade; Gênero; Identidades coletivas; Movimento homossexual; Mercado segmentado.

O presente artigo tem por objetivo explorar as relações entre o movimento homossexual e o mercado de consumo segmentado dirigido a este público em São Paulo. A partir do drama social analisado no texto, envolvendo militantes homossexuais e travestis, atores do mercado segmentado e do público que o freqüenta, pretende-se traçar caminhos para a compreensão dessas relações, bem como de alguns processos relativos à constituição do sujeito político do movimento homossexual num contexto de multiplicação de categorias identitárias e desestabilização desse sujeito.
"EACH ONE TO HIS TRADE"? POWER, IDENTITY, AND SEGMENTATION OF MARKET IN THE HOMOSEXUAL MOVEMENT

Isadora Lins França

Keywords: Sexuality; Gender; Collective identities; Homosexual movement; Segmented market.

The present article aims at exploring the relations between the homosexual movement and the segmented consumption market directed at such public in São Paulo. Starting with the social drama analyzed in the text, which involves militant homosexuals and transvestites, the so-called actors of such segmented market, and the attending public, we intend to delineate ways to understand these relations, as well as some processes related to the constitution of the political subject of the homosexual movement in a context of both multiplication of identifying categories and destabilization of this subject.
"CHACUN À SA PLACE ?": POUVOIR, IDENTITÉ ET SEGMENTATION DU MARCHÉ PAR RAPPORT AU MOUVEMENT HOMOSEXUEL

Isadora Lins França

Mots-clés: Sexualité; Genre; Identités collectives; Mouvement homosexuel; Marché segmenté.

Le but de cet article est d'exploiter les rapports entre le mouvement homosexuel et le marché de consommation segmenté dirigé à ce public à São Paulo. À partir du drame social analysé dans le texte, dont font partie des militants homosexuels et des travestis, acteurs du marché segmenté, ainsi que le public qui le fréquente, nous proposons des voies pour la compréhension de ces relations, ainsi que de certains processus relatifs à la constitution du sujet politique $\mathrm{du}$ mouvement homosexuel dans un contexte de multiplication de catégories identitaires et de déstabilisation de ce sujet.. 